\title{
Large-scale manufacturing route to metamaterial coatings using thermal spray techniques and their response to solar radiation
}

\author{
Nadimul Haque Faisal ${ }^{1} \cdot$ Nazmi Sellami $^{1} \cdot$ Federico Venturi $^{2} \cdot$ Tanvir Hussain $^{2} \cdot$ Tapas Mallick $^{3}$. \\ Firdaus Muhammad-Sukki ${ }^{4}$ - Alex Bishop ${ }^{5} \cdot$ Hari Upadhyaya ${ }^{6} \cdot$ Nirmal Kumar Katiyar $^{6} \cdot$ Saurav Goel ${ }^{5,6,7}$
}

Received: 9 April 2021 / Accepted: 18 June 2021 / Published online: 4 July 2021

(C) The Author(s) 2021

\begin{abstract}
Metamaterials, an artificial periodic two- or three-dimensional configuration, can change propagation characteristics of electromagnetic waves (i.e., reflection, transmission, absorption). The current challenges in the field of metamaterial coatings are their manufacturing in a large-scale and large-length scale. There is a clear need to enhance process technologies and scalability of these. Thermal spraying is a method used to deposit small- to large-scale coatings where the sprayed layer is typically formed by the successive impact of fully or partially molten particles of a material exposed to various process conditions. This work aims to investigate the feasibility to manufacture large scale metamaterial coatings using the thermal spray technique and examine their response to solar radiation. Two types of coatings namely, $\mathrm{Cr}_{2} \mathrm{O}_{3}$ and $\mathrm{TiO}_{2}$, were deposited onto various substrates (e.g., steel, aluminium, glass, indium tin oxide (ITO)-coated glass) with a fine wire mesh (143 $\mu \mathrm{m}$ and $1 \mathrm{~mm}$ aperture sizes) as the masking sheet to manipulate the surface pattern using suspension high-velocity oxy-fuel thermal spraying (S-HVOF) and atmospheric plasma-sprayed (APS) methods, respectively. Post deposition, their responses subjected to electromagnetic wave (between 250 and $2500 \mathrm{~nm}$ or ultraviolet (UV)-visible (Vis)-infrared (IR) region) were characterised. The additional microstructural characterisation was performed using scanning electron microscopy (SEM), energy-dispersive X-ray spectroscopy (EDS), X-ray diffraction (XRD), three-dimensional profilometry, and optical spectroscopy. It is demonstrated that through novel application of thermal spray techniques, large-scale manufacturing of metamaterial coating is possible, and such material can affect electromagnetic wave propagation. Comparison between $\mathrm{Cr}_{2} \mathrm{O}_{3}$ and $\mathrm{TiO}_{2}$ coatings on aluminium substrates showed reduced three orders of reduced reflectance for $\mathrm{Cr}_{2} \mathrm{O}_{3}$ coatings (for 1-mm aperture size) throughout the spectrum. It was concluded that for a similar bandgap, $\mathrm{Cr}_{2} \mathrm{O}_{3}$ coatings on aluminium substrate will yield improved optical performance than $\mathrm{TiO}_{2}$ coating, and hence more useful to fabricate opto-electronic devices.
\end{abstract}

Keywords Electromagnetic wave $\cdot$ Optical properties $\cdot$ Thermal spray coatings $\cdot$ APS $\cdot$ S-HVOF $\cdot$ Solar radiation

\section{Nomenclature}

$\begin{array}{ll}\text { A } & \text { Absorptivity } \\ \AA & \text { Angstrom (film thickness) } \\ \text { C } & \text { Speed of light }\end{array}$

Highlights • We present a novel way for large-scale manufacturing of metamaterial coatings.

- All types of coatings studied showed their ability to respond to solar radiation (between $250 \mathrm{~nm}$ to $2500 \mathrm{~nm}$ or ultraviolet/UVvisible/Vis-infrared/IR region).

- For the same bandgap, $\mathrm{Cr} 2 \mathrm{O} 3$ coating on an aluminium substrate (as opposed to $\mathrm{TiO} 2$ ) showed better optical performance.

- Liquid deposition techniques can enable the manufacture of finely grained (nanometre, submicrometre) composite coatings.

Nadimul Haque Faisal

N.H.Faisal@rgu.ac.uk

Extended author information available on the last page of the article

$\begin{array}{ll}\varepsilon & \text { Dielectric permittivity (or dielectricconstant) } \\ \mathrm{E} & \text { Energy of photon } \\ \mathrm{Eg} & \text { Gap (band) energy } \\ \mathrm{h} & \text { Planck's constant } \\ \lambda & \text { Wavelength } \\ \lambda_{0} & \text { Free-spacewavelength } \\ \mu & \text { Magneticpermeability } \\ \Omega & \text { Ohm (electrical resistance) } \\ R & \text { Reflectivity } \\ T & \text { Transmittivity } \\ 2 \mathrm{D} / 3 \mathrm{D} & \text { Two or three-dimensional } \\ \mathrm{ALD} & \text { Atomic layer deposition } \\ \text { APS } & \text { Atmospheric plasma-sprayed } \\ \text { DC } & \text { Direct current } \\ \text { EDS } & \text { Energy dispersive X-ray spectroscopy } \\ \text { GRIN } & \text { Graded index } \\ \text { HVPE } & \text { Hydride vapor phase epitaxy }\end{array}$




$\begin{array}{ll}\text { IR } & \text { Infrared } \\ \text { ITO } & \text { Indium tin oxide } \\ \text { LPE } & \text { Liquid phase epitaxy } \\ \text { MBE } & \text { Molecular beam epitaxy } \\ \text { MIR } & \text { Middle infrared region } \\ \text { MOMBE } & \text { Metal-organic molecular beam epitaxy } \\ \text { NIR } & \text { Near infrared region } \\ \text { RPM } & \text { Rotation per minute } \\ \text { S-HVOF } & \text { Suspension high-velocity oxy-fuel thermal } \\ & \text { spraying } \\ \text { SEM } & \text { Scanning electron microscopy } \\ \text { UV } & \text { Ultraviolet } \\ \text { Vis } & \text { Visible } \\ \text { XRD } & \text { X-ray diffraction }\end{array}$

\section{Introduction}

The metamaterials show unique properties of electromagnetic wave propagation (reflection/transmission/absorption) by confining the wave within the materials due to its unique properties and geometrical arrangement. The geometrical arrangement of the coatings at small length scales (atomic to micro-scale) can be used to manipulate electromagnetic wave propagation. Artificial periodic configuration allows achieving the targeted material properties which would not be available from pristine materials. These unique properties can change the propagation characteristics of electromagnetic waves in the solar spectrum, which in turn can cause electromagnetic wave energy to concentrate in some specific frequency bands. These properties can be used in stealth applications for radiofrequency and microwave components to make components such as rectenna, a device proposed for a wide range of applications, particularly wireless electrical power transmission, and various radio-powered devices [1]. Other example applications including tunable filters, amplifiers and oscillators, dielectric resonators for radio waves in antennas [2], and more avenues are growing in the field of optics and photonics (e.g., negative refraction, perfect lenses, cloaking, perfect absorbers) [3]. The idea that the metamaterial can manipulate electromagnetic wave distribution has led to new research works including, for example, improving gain and directivity of the microstrip antenna [4], as well as antennas with different tunable functions in microwave band [5].

Among different dielectric materials, metal oxides present excellent properties like high resistance to environmental degradation, resistance to oxidation, and appropriate mechanical properties. Additionally, such materials present suitable electromagnetic properties, like high relative dielectric permittivity $(\varepsilon)$ and magnetic permeability $(\mu)$, which favour their use in telecommunication devices. It is important to highlight that the dimension of an antenna is of the order of $\lambda_{0} \varepsilon^{-0.5}$ where $\lambda_{0}$ is the free-space wavelength and $\varepsilon$ is the dielectric constant; therefore, the antenna size can reduce significantly by choosing a substrate with a high value of dielectric permittivity $(\varepsilon)$ [6]. There are various techniques for metamaterials coating fabrication like molecular beam epitaxy (MBE), hydride vapour phase epitaxy (HVPE), liquid phase epitaxy (LPE), metal-organic molecular beam epitaxy (MOMBE), and atomic layer deposition (ALD). It is important to note that such techniques suffer from limited build volume, low-throughput speed, problems in scalability, and high manufacturing cost. While such deposition techniques have their advantages, the choice of fabrication method is a critical choice that dictates the resolution, material, and working frequency of the resultant metamaterial [7]. Current challenges in the field of metamaterial coatings are their manufacturing in micro- to millimeter-length scale, including technologies and approaches to combine and repeat with variation. The inability to adequately manufacture large-scale metamaterial coatings (or metasurfaces with micro functionality) can restrict the ability to handle and fabricate disparate materials including issues related to joint robustness across length scales. Hence, there is a clear need to not only enhance process technologies for enhanced resolution but also enhance the scalability of these.

The thermal spray coating method is an agile and scalable technique which can deposit materials to possess semiconducting properties. A recent trend in spray technology (allowed using suspension/solution feedstock) has been focussed on introducing nanostructure or finer microstructures and precision-engineered surface finish. By a highly engineered design of thermal spray process, e.g., selection of particle shape, geometry, size, crystal structure, and arrangement, one can tailor the interaction of the electromagnetic wave unconventionally hitherto not achievable by any other large-scale precision additive technologies. During the thermal spray coating process (powder-based feedstock), a coating is built up from powder particles (typically from few tenths of micrometres to nanometres) and not from atoms or molecules. Any particle used in thermal spraying remains molten in a flame for few milliseconds and then solidifies rapidly within few microseconds [8]. However, some metastable phases could form during rapid solidification. As such, unlike atomistic film deposition methods such as reactive evaporation or reactive sputtering, conventional thermal spraying does not offer the flexibility for the synthesis of new compounds during processing [9], but this is also possible using suspension/solution precursor spray which is not widespread in industries as yet.

Some of the earlier works have investigated the optical properties of metal oxides fabricated using conventional plasma spray [9] and suspension plasma spray techniques [10]. Applications such as solar energy receiver require reduction of thermal losses, high absorptivity across the 
whole solar emission wavelength range ( 300 to $3000 \mathrm{~nm}$, or 100 to $1000 \mathrm{THz}$ ) as well as low emissivity in the medium infrared greater than $3000 \mathrm{~nm}$. In this case, since transparency is no longer required, thicker coatings (possible through thermal spray) can be applied on metal substrates [9]. For example, Tului et al. [9] used powders of $\mathrm{ZnO}$ and $\mathrm{ZnO}+(3 \mathrm{wt} . \%$ and $22 \mathrm{wt} . \%) \mathrm{Al}_{2} \mathrm{O}_{3}$ for plasma spray onto sand-blasted steel substrates and obtained thicker coatings of $\mathrm{ZnO}$ doped with aluminium ( $\mathrm{Al}$ ). It is important to note that $\mathrm{Al}_{2} \mathrm{O}_{3}$ (a dielectric) is more stable and more difficult to reduce than $\mathrm{ZnO}$ (a semiconductor). It was observed that the infrared emissivity of sprayed coatings depends on various factors such as wavelength, the chemical composition of initial powders, and the atmosphere of spraying. Vaßen et al. [10] deposited highly porous $\mathrm{TiO}_{2}$ coatings using suspension plasma spraying on indium tin oxide (ITO)-coated glass substrates for photovoltaic cells, with special emphasis on the establishment of a high-volume fraction of the desired anatase phase. They obtained coatings containing $90 \%$ of the anatase phase (based on photocurrent voltage characteristic curve). Based on these results, they suggested that the thermal spray technology could be a favourable method to produce a coating with submicron and even nanocrystalline microstructure without the need for heat treatment. As indicated by Bégard et al. [11], for a thin coating to achieve high and broadband absorption, the permeability and the magnetic losses must be high. On the other hand, the advantage of electrical losses can be exploited to increase the absorption by using a somewhat thicker coating. In a work by Bartuli et al. [12], non-conventional ceramic-based composite coatings were fabricated by air plasma spraying to evaluate their tailored electromagnetic properties. Different chromia $\left(\mathrm{Cr}_{2} \mathrm{O}_{3}\right)$-based feedstock materials were used for the fabrication of samples with an average thickness of about $3 \mathrm{~mm}$. The complex formulation (i.e., in terms of ceramic matrix and metallic dispersions) can be used to produce functional single layer, and possibly multilayer coatings. The use of metallic dispersions helps increase complex permittivity and permeability in dielectric matrix composites. Due to the high thermal and oxidation resistance of spinel (oxides), recently, Deng et al. [13] studied plasma-sprayed vanadium tailings deposited onto stainless-steel substrate with $\mathrm{Ni} / \mathrm{Al}$ bond layer. Vanadium tailings are composed of oxides of $\mathrm{Fe}$, $\mathrm{Cr}, \mathrm{Mn}, \mathrm{V}, \mathrm{Ti}$, and other transition metals and are a by-product of steel manufacturing. The spinel structured composite oxide coatings with low-energy band gaps exhibited high absorptance, emissivity, and high thermal stability.

Therefore, if one desires to obtain selective properties, then there can be many permutations of materials possible. Chromium oxide $\left(\mathrm{Cr}_{2} \mathrm{O}_{3}\right)$ is a p-type semiconductor material with a wide bandgap $\left(\mathrm{E}_{\mathrm{g}} \approx 3.0 \mathrm{eV}\right)$ [14]. This kind of p-type wide bandgap oxide semiconductor is a potential candidate for ultraviolet (UV)-light emitter using nano-lasers and optical storage system. The dielectric constant $(\varepsilon)$ of $\mathrm{Cr}_{2} \mathrm{O}_{3}$ at room temperature in the wide-frequency region $(100 \mathrm{~Hz}$ to $30 \mathrm{MHz}$, i.e., frequency-dependent) varies between 350 and 25 (i.e., the value decreases with an increase in frequency) [14]. Titanium dioxide $\left(\mathrm{TiO}_{2}\right)$ is another dielectric material that has been extensively investigated for the fabrication of radiofrequency and microwave components [15], and it is an n-type semiconductor, but has the potential to be a p-type in undoped form (from bulk to nano-level crystal) [16, 17]. There are three normal crystal phases for $\mathrm{TiO}_{2}$ material with different band gaps (i) brookite ( 3.0 to $3.6 \mathrm{eV}$ ), (ii) anatase $(3.2 \mathrm{eV})$, and (iii) rutile $(3.0 \mathrm{eV})$. The dielectric constant $(\varepsilon)$ of rutile $\mathrm{TiO}_{2}$ at room temperature is about 63.7 [18].

Metamaterial fabrication using thermal spray techniques is poised to make a huge impact primarily because it can route, or shape electromagnetic waves as demonstrated in a recent work on another type of electromagnetic wave (i.e., radar) absorbing application by Shao et al. [19]. Fabrication of thermally sprayed metamaterial (periodic configuration) coatings responding to solar radiation are yet to be investigated and based on the results shown in this work, we claim that this is indeed viable. Thermal spray can be an enabling technology to purpose design and synthesize newer category of metamaterial coatings. In this work, an artificial periodic planar configuration (through single layer spraying) fabrication scheme has been implemented using suspension highvelocity oxy-fuel (S-HVOF) thermal spray and atmospheric plasma spray (APS) coating methods. While exploring materials and designs of metamaterial coatings, microstructure as well as their optical characterisation (between 250 and $2500 \mathrm{~nm}$, i.e., Ultraviolet (UV)-visible (Vis)-infrared (IR) light region) are performed. Results obtained from different materials and designs of metamaterial coatings are compared to assess the influence on the electromagnetic wave propagation characteristics in the solar spectrum.

\section{Materials and methods}

Metamaterials gain their properties not from their composition, but purpose-designed artificial structures. Accordingly, this work examined to explore the feasibility of design and fabricating an artificial periodic planar configuration using suspension high-velocity oxy-fuel (S-HVOF) thermal spray and atmospheric plasma-spray (APS) coating methods, followed by their microstructural, material, and optical characterisation.

\subsection{Coating and substrate materials}

The different types of substrates used in this study were mild carbon steel, pure aluminium, glass slide, and indium tin oxide coated glass slides (ITO: $\operatorname{In}_{2} \mathrm{O}_{3} / \mathrm{SnO}_{2}$, note: ITO

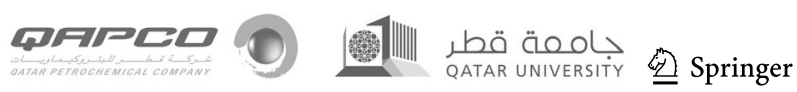


coated on both sides of the glass). The metal substrates were supplied by Laser Master, UK, whereas transparent glass slides (product code: S8902-1PAK) and ITOcoated glass slide (with 150-300 ̊ film thickness, transmittance $>87 \%$, refractive index: 1.517 ; product code: 576,352) were obtained from Sigma-Aldrich, UK. The substrates were cleaned using industrial methylated spirit to remove any debris or grease prior to the deposition. The details of coatings. substrate, spray gun distances, aperture or mesh sizes, dimensions, and surface preparation are shown in Table 1.

It is important to note that the metals used (e.g., mild steel, aluminium) as substrates are excellent reflectors for visible light, and their dielectric constant is the highest or infinite. On the other hand, ITO-coated glass, which is an n-type semiconductor with a band gap of $4 \mathrm{eV}$ as high electrical conductivity $\left(10^{-5} \Omega \mathrm{cm}\right)$ and high optical transparency (85\%) [20]. A commercially available suspension of $\mathrm{Cr}_{2} \mathrm{O}_{3}$ purchased from Millidyne Oy (Tampere, Finland) was used as one of the coating feedstock materials. The solid content in the $\mathrm{Cr}_{2} \mathrm{O}_{3}$ suspension was 20 wt. $\%$ of $\mathrm{Cr}_{2} \mathrm{O}_{3}$ (>99\% purity) in water, and the size of the particles was $370 \pm 140 \mathrm{~nm}$. Similarly, the $\mathrm{TiO}_{2}$ agglomerated and sintered $\mathrm{TiO}_{2}$ feedstock powder material (with dark grey) was used as another material with spheroidal morphology (METCO$6231 \mathrm{~A}$ ) obtained from Sulzer Metco, Germany. The original particle size of $\mathrm{TiO}_{2}$ was $-105+32 \mu \mathrm{m}$ (Note: a plus sign before the sieve mesh indicates the particles are retained by the sieve, a minus sign before the sieve mesh indicates the particles pass through the sieve, and about $90 \%$ or more of the particles will lie within the indicated range. For example, if the particle size of $\mathrm{TiO}_{2}$ is described as $-105+32$ mesh, then $90 \%$ or more of the material will pass through a 105 mesh sieve and be retained by a 32-mesh sieve).

\subsection{Substrate assembly and deposition}

The substrate was fixed in the coating booth and the thermal spray gun facing surface was masked with the masking sheets, which was made from woven wire mesh of 304L stainless-steel (melting point: 1400 to $1450{ }^{\circ} \mathrm{C}$ ) as shown in Fig. 1a, and the optical photograph of the masked substrate in coating booth as shown in Fig. 1b, c. Two different sized apertures used were $143 \mu \mathrm{m}$ (mesh wire diameter of $80 \mu \mathrm{m}$ ) and $1 \mathrm{~mm}$ (mesh wire diameter of $400 \mu \mathrm{m}$ ). The assembly helped in the manufacturing of a 3D square slab with periodic configuration (locally isotropic) using the thermal spray technique in a scalable way; i.e., the entire coating process was completed in about one minute.

The two thermal spray techniques, air plasma spray (APS) and suspension-high-velocity oxy-fuel (S-HVOF), were used for the deposition of array structures. S-HVOF is a promising method to improve coating properties as it enables powder feedstock too small to be processed by mechanical feeders to be sprayed in suspension form [21], allowing the production of coatings with improved density and homogeneity [22]. In this work, both S-HVOF (for $\mathrm{Cr}_{2} \mathrm{O}_{3}$ ) and APS (for $\mathrm{TiO}_{2}$ ) methods were applied to study, whether the sprayed powder could pass through the masking sheet and form periodic coating configurations. Therefore, the coating was deposited by changing the distance of the spray gun from the substrate $\left(85 \mathrm{~mm}\right.$ and $120 \mathrm{~mm}$ for $\mathrm{Cr}_{2} \mathrm{O}_{3}$ spraying). The $\mathrm{Cr}_{2} \mathrm{O}_{3}$ coating was sprayed using a TopGun HVOF spray unit (GTV GMBH, Germany) with an axial injection

Table 1 Details of the different kinds of substrate used for thermal spray coating

\begin{tabular}{llllll}
\hline Coating materials & Substrate materials & Spray gun distance & $\begin{array}{l}\text { Masking aperture } \\
\text { (or mesh size) }\end{array}$ & Substrate geometry & $\begin{array}{l}\text { Surface preparation of } \\
\text { substrate before thermal } \\
\text { spray coating }\end{array}$ \\
\hline S-HVOF Cr ${ }_{2} \mathrm{O}_{3}$ coating & Mild (carbon) steel & $85 \mathrm{~mm}$ & $1 \mathrm{~mm}$ & $120 \mathrm{~mm} \times 50 \mathrm{~mm} \times 5 \mathrm{~mm}$ & - \\
& Mild (carbon) steel & $85 \mathrm{~mm}$ & $143 \mu \mathrm{m}$ & $120 \mathrm{~mm} \times 50 \mathrm{~mm} \times 1 \mathrm{~mm}$ & - \\
& Aluminium & $85 \mathrm{~mm}$ & $1 \mathrm{~mm}$ & $120 \mathrm{~mm} \times 50 \mathrm{~mm} \times 2 \mathrm{~mm}$ & - \\
& Aluminium & $85 \mathrm{~mm}$ & $143 \mu \mathrm{m}$ & $120 \mathrm{~mm} \times 50 \mathrm{~mm} \times 2 \mathrm{~mm}$ & - \\
& Aluminium & $120 \mathrm{~mm}$ & $143 \mu \mathrm{m}$ & $120 \mathrm{~mm} \times 50 \mathrm{~mm} \times 2 \mathrm{~mm}$ & - \\
APS TiO ${ }_{2}$ coating & Mild (carbon) steel & $120 \mathrm{~mm}$ & $143 \mu \mathrm{m}$ & $120 \mathrm{~mm} \times 50 \mathrm{~mm} \times 1 \mathrm{~mm}$ & - \\
& Mild (carbon) steel & $120 \mathrm{~mm}$ & $1 \mathrm{~mm}$ & $120 \mathrm{~mm} \times 50 \mathrm{~mm} \times 1 \mathrm{~mm}$ & - \\
& Mild (carbon) steel & $120 \mathrm{~mm}$ & $143 \mu \mathrm{m}$ & $120 \mathrm{~mm} \times 50 \mathrm{~mm} \times 1 \mathrm{~mm}$ & Sand blasted \\
& Aluminium & $120 \mathrm{~mm}$ & $143 \mu \mathrm{m}$ & $120 \mathrm{~mm} \times 50 \mathrm{~mm} \times 2 \mathrm{~mm}$ & - \\
& Aluminium & $120 \mathrm{~mm}$ & $1 \mathrm{~mm}$ & $120 \mathrm{~mm} \times 50 \mathrm{~mm} \times 2 \mathrm{~mm}$ & - \\
& Glass & $120 \mathrm{~mm}$ & $143 \mu \mathrm{m}$ & $75 \mathrm{~mm} \times 25 \mathrm{~mm} \times 1 \mathrm{~mm}$ & - \\
& Glass & $120 \mathrm{~mm}$ & $1 \mathrm{~mm}$ & $75 \mathrm{~mm} \times 25 \mathrm{~mm} \times 1 \mathrm{~mm}$ & - \\
& ITO-coated glass & $120 \mathrm{~mm}$ & $143 \mu \mathrm{m}$ & $75 \mathrm{~mm} \times 25 \mathrm{~mm} \times 1 \mathrm{~mm}$ & Sand blasted \\
& ITO-coated glass & $120 \mathrm{~mm}$ & $1 \mathrm{~mm}$ & $75 \mathrm{~mm} \times 25 \mathrm{~mm} \times 1 \mathrm{~mm}$ & - \\
\hline
\end{tabular}


Fig. 1 Experimental scheme. a Substrate and masking sheet assembly, $\mathbf{b}$ fabrication scheme of thermally sprayed coatings (artificial periodic configuration) on various substrates, and c optical photograph of spray views showing the assembly of sample with masking sheet and frame, sample at S-HVOF coating booth and $\mathbf{d}$ APS coating booth. e Schematics of configurational coating on metal and glass

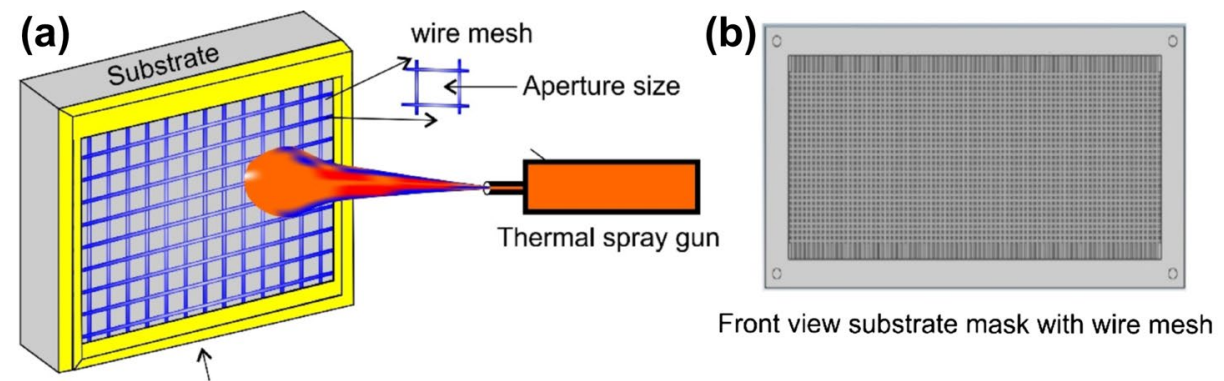

Frame holding the mesh

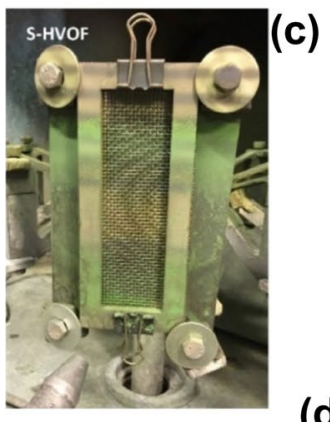

(d)

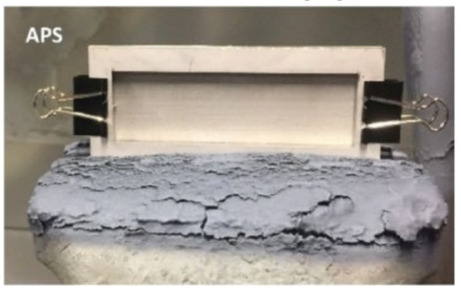

3D configuration thermally sprayed coating

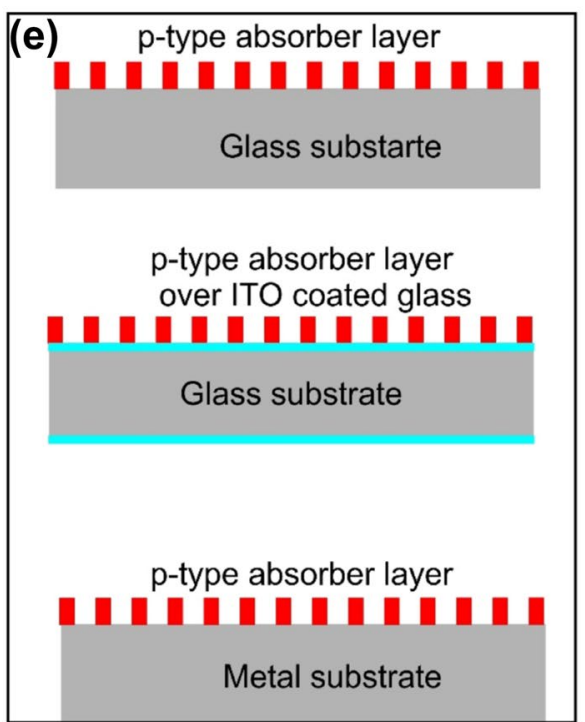

of suspension feedstock directly into the combustion chamber using an oxygen flow rate of $198 \mathrm{l} / \mathrm{min}$ and hydrogen flow rate of $463 \mathrm{l} / \mathrm{min}$, yielding $65 \mathrm{~kW}$ flame power. The suspension was delivered from a pressurized vessel which resulted in a feed rate of $30 \mathrm{ml} / \mathrm{min}$. The substrates were then mounted at $85-\mathrm{mm}$ and $120-\mathrm{mm}$ stand-off distance onto a rotating carousel with a vertical axis of rotation operating at 72 RPM, while the spray gun traverses (single pass) along the vertical axis at a speed of $20 \mathrm{~mm} / \mathrm{s}$. The spray angle was $90^{\circ}$ and during spraying, the samples were not cooled. APS was carried using a $3 \mathrm{MB}$ torch and 7MC-50 console, Sulzer Metco. The powders were directly sprayed onto the substrates with only one stand-off distance. The optimised process parameters chosen were current of 500 amperes, auxiliary $\mathrm{H}_{2}$ gas flow: $60 \%$, stand-off distance: $120 \mathrm{~mm}$, step height: $10 \mathrm{~mm}$, transverse speed: $2000 \mathrm{~m} / \mathrm{s}$, powder feed rate: $70 \mathrm{~g} / \mathrm{min}$ and spray angle: $90^{\circ}$.

\subsection{Material characterisation}

The morphological characterisation of the coated surface was performed using an SEM and an EDS (Karl Zeiss EVO LS10 and JEOL JSM 6010 LA, respectively). Threedimensional non-contact profilometry of the artificial periodic-coated surface was performed using a Nanovea HS2000 profilometer, with L2 optical pen which had a lateral accuracy of $2 \mu \mathrm{m}$, pitch $10 \mu \mathrm{m}$, and height range of $950 \mu \mathrm{m}$. XRD data was recorded using Siemens D5005 from Bruker using Copper k $\alpha$ wavelength of $1=1.54056 \AA$. The sun is a natural source of terahertz (THz) electromagnetic waves, and the solar emission wavelength range is 300 to $3000 \mathrm{~nm}$, or 100 to $1000 \mathrm{THz}$. In this work, the optical measurements were carried in the solar spectrum wavelength between 250 and $2500 \mathrm{~nm}$; i.e., scan range is from ultraviolet (UV)-visible (Vis)-infrared (IR) light. During the interaction of an electromagnetic wave with a material, the wave is reflected, absorbed, or transmitted according to the relation $R+A+T=1$, where $R$ is reflectivity, $A$ is absorptivity, and $T$ is transmittivity. For samples like steels, the transmissivity $(T)$ is zero, and thus, absorptivity can be calculated from $A=1-R$. However, the electromagnetic wave can also get refracted and/or scattered in samples with partial ceramic coatings (metamaterial type) and glass/metallic substrates. In this work, UV-Vis-NIR spectroscopy measurement (reflection, absorption, transmission) was performed using a Perkin Elmer Lambda 950 spectrophotometer in reflectance mode between 250 and $2500 \mathrm{~nm}$ wavelength range (i.e., ultraviolet/UV region: 250 to $400 \mathrm{~nm}$; visible region:

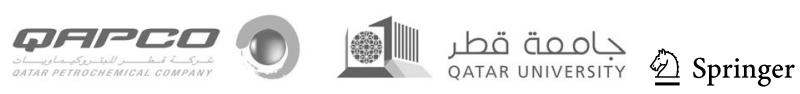


400 to $700 \mathrm{~nm}$; near-infrared region (NIR): 700 to $1400 \mathrm{~nm}$; middle infrared region (MIR): 1400 to $2500 \mathrm{~nm}$ ). Table 2 shows the solar spectrum wavelength range, i.e., ultraviolet, visible to middle infrared light.

\section{Results and discussion}

\subsection{Coating microstructure and phase characterisation}

The reduction of the reflectance and increasing absorption can be achieved through the metamaterials and their geometrical manipulation over the surface to trap the incoming radiations [19]. Therefore, the surface geometrical manipulation was performed by using different sizes of aperture (or mesh) and two different materials coating over metal surface (aluminium, steel) as well as glass substrates (plane glass, ITO-coated glass). The artificial three-dimensional (3D) periodic planar configurational geometry coatings were deposited using different aperture/mesh size (of masking sheet) as shown in Fig. 2a-e. The S-HVOF spray method was used for $\mathrm{Cr}_{2} \mathrm{O}_{3}$ and APS method was used for $\mathrm{TiO}_{2}$ coating with two different aperture sizes $(143 \mu \mathrm{m}$ and $1 \mathrm{~mm})$. The SEM image reveals that the $\mathrm{Cr}_{2} \mathrm{O}_{3}$ coating produced by the $\mathrm{S}-\mathrm{HVOF}$ showed a good $3 \mathrm{D}$ periodic configuration even at $143-\mu \mathrm{m}$ aperture size. Contrarily, the $\mathrm{TiO}_{2}$ coating deposited by the APS method did not show controlled periodicity (but periodic configuration is indicative) for $143-\mu \mathrm{m}$ aperture size.

A good periodicity for $\mathrm{TiO}_{2}$ coating was obtained by using a 1-mm aperture as shown in Fig. 2e. Furthermore, the $3 \mathrm{D}$ configuration and the height of the islands by both deposition methods were confirmed by non-contact profilometry, showing distinct thin orthogonal structures. For $\mathrm{Cr}_{2} \mathrm{O}_{3}$ coatings, the mean height of the orthogonal structure varies between 124 and $755 \mathrm{~nm}$ (for 143- $\mu \mathrm{m}$ and 1-mm aperture sizes), whereas for $\mathrm{TiO}_{2}$ coatings, the mean height of the orthogonal structure varies between 12 and $17 \mu \mathrm{m}$ (for 143$\mu \mathrm{m}$ and 1-mm aperture sizes, e.g., $15 \mu \mathrm{m}$, shown in Fig. $2 \mathrm{f}$ for $143-\mu \mathrm{m}$ aperture size), and the gap between orthogonal structures typically matched with the mesh wire diameter of $80 \mu \mathrm{m}$ and $400 \mu \mathrm{m}$. The quality of coating depends strongly on its microstructure. Therefore, the microstructure of the developed coatings $\left(\mathrm{Cr}_{2} \mathrm{O}_{3}\right.$ and $\left.\mathrm{TiO}_{2}\right)$ is shown via SEM micrographs in Fig. 3 a and c; the inset shows the high magnification micrograph. In these micrographs, mainly the presence of surface connected open-ended porosity was observed for the $\mathrm{Cr}_{2} \mathrm{O}_{3}$ coatings, including features like voids, unmolten particle, non-bonded inter-splat areas, as featured in Fig. 3a. APS-sprayed $\mathrm{TiO}_{2}$ coating micrographs also showed features that include fewer voids/unmolten particle/non-bonded inter-splat areas, but high-density cracks in splats. The splats for APS-sprayed $\mathrm{TiO}_{2}$ coatings appeared more cohesive, whereas, for S-HVOF-sprayed $\mathrm{Cr}_{2} \mathrm{O}_{3}$ coatings, the splat features were not clear and were less cohesive. The differences in a splat and associated features (in this case between $\mathrm{Cr}_{2} \mathrm{O}_{3}$ and $\mathrm{TiO}_{2}$ ) are due to different powder sizes and spray techniques [23], resulting in different temperatures and velocities of the particles throughout the processes [24].

As shown in Fig. 3c, the constraining of splats led to the formation of sub-microscopic vertical cracks of splats and their coalescence resulted in a typical brittle fracture of $\mathrm{TiO}_{2}$ coatings. Such vertical cracks in the splats were not observed in the $\mathrm{Cr}_{2} \mathrm{O}_{3}$ coatings. The $\mathrm{TiO}_{2}$ coatings appear to have fewer gaps or voids between splats, indicating relatively higher bond strength. High splat layering in $\mathrm{TiO}_{2}$ coatings may have resulted in high density in the plasma coatings. Also, despite the glass substrate having low roughness, the $\mathrm{TiO}_{2}$ particles adhered to it without much difficulty. The elemental analysis of coatings by EDS confirmed the presence of various expected elements in each coating, mainly dominated by chromium and oxygen in S-HVOF coatings and titanium and oxygen in APS coating. The presence of iron $(\mathrm{Fe})$ peaks in the EDS spectrum of $\mathrm{Cr}_{2} \mathrm{O}_{3}$ coating are related to the base substrate of mild steel, which in turn confirms the low thickness of the coating, as shown in Fig. 3 $\mathrm{c}$ and $\mathrm{d}$.

Figure 4 shows the results of the XRD patterns of the artificial periodic $3 \mathrm{D}$ configuration coated $\left(\mathrm{Cr}_{2} \mathrm{O}_{3}, \mathrm{TiO}_{2}\right)$ surface on mild steel substrates, sprayed through $143-\mu \mathrm{m}$
Table 2 Solar electromagnetic wave radiation types (wavelength range is from ultraviolet, visible to infrared light)

\begin{tabular}{llll}
\hline Solar spectrum region & Wavelength & Frequency $\left(1 \mathrm{~Hz}=10^{-12} \mathrm{THz}\right)$ & Photon energy \\
\hline Ultraviolet (100 to $400 \mathrm{~nm})$ & $100 \mathrm{~nm}$ & $3.0 \times 10^{15} \mathrm{~Hz}(3000 \mathrm{THz})$ & $12.30 \mathrm{eV}$ \\
- UVA (315-400 nm) & $250 \mathrm{~nm}$ & $1.2 \times 10^{15} \mathrm{~Hz}(1200 \mathrm{THz})$ & $4.95 \mathrm{eV}$ \\
- UVB (280-315 nm) & & & \\
- UVC (100-280 nm) & & $7.5 \times 10^{14} \mathrm{~Hz}(750 \mathrm{THz})$ & $3.10 \mathrm{eV}$ \\
Visible (400 to $700 \mathrm{~nm})$ & $400 \mathrm{~nm}$ & $4.3 \times 10^{14} \mathrm{~Hz}(430 \mathrm{THz})$ & $1.80 \mathrm{eV}$ \\
& $700 \mathrm{~nm}$ & $2.1 \times 10^{14} \mathrm{~Hz}(215 \mathrm{THz})$ & $0.89 \mathrm{eV}$ \\
Infrared (700 to $1 \mathrm{~mm})$ & $1400 \mathrm{~nm}$ & $1.2 \times 10^{14} \mathrm{~Hz}(120 \mathrm{THz})$ & $0.49 \mathrm{eV}$ \\
- NIR (700-1400 nm) & $2500 \mathrm{~nm}$ & & \\
\hline MIR (1400-3000 nm) & & &
\end{tabular}



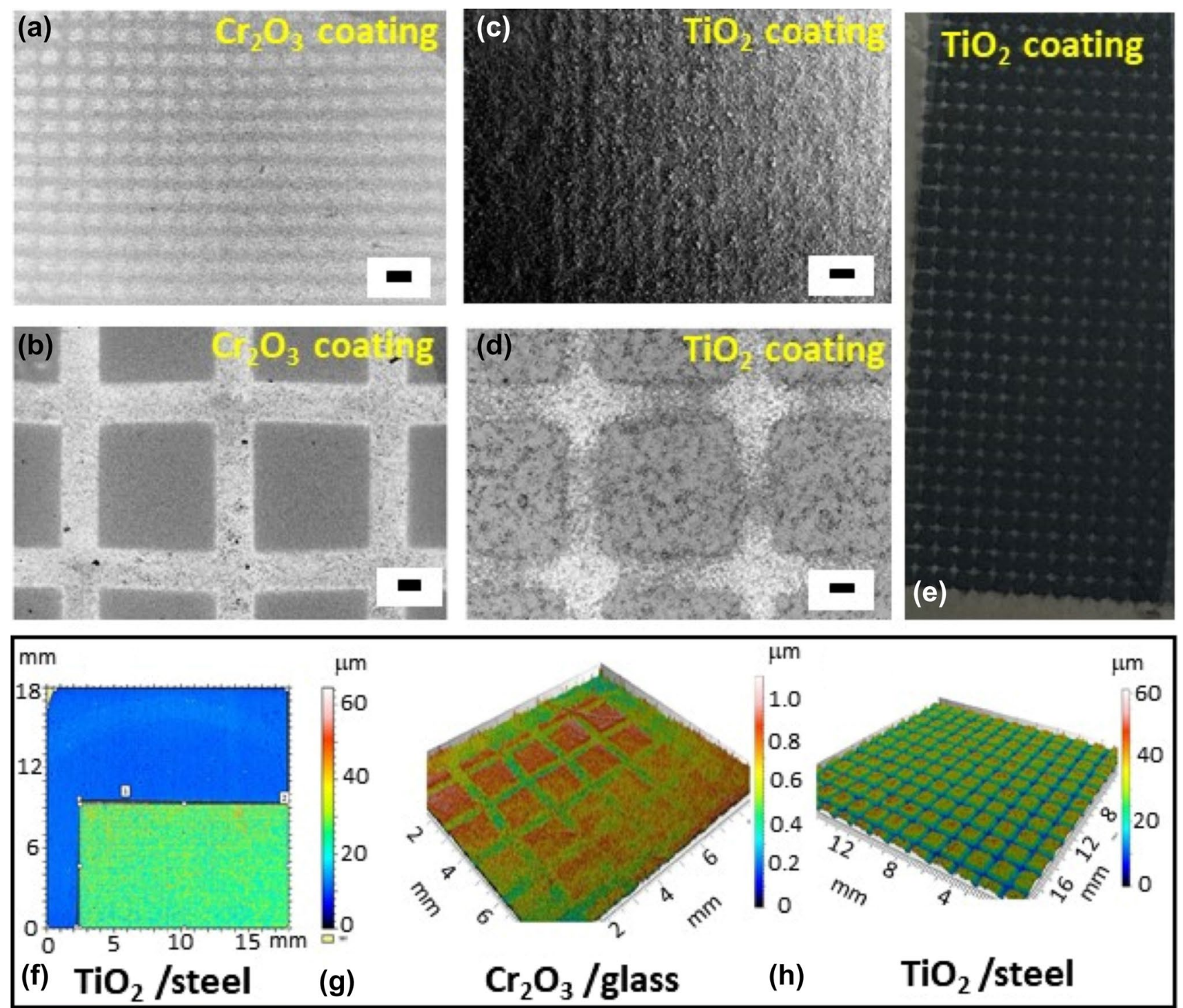

Fig. 2 Three-dimensional (3D) artificial periodic configuration; SEM micrograph of S-HVOF sprayed $\mathrm{Cr}_{2} \mathrm{O}_{3}$ coatings a aperture size $143 \mu \mathrm{m}$, b aperture size $1 \mathrm{~mm}$; APS-sprayed $\mathrm{TiO}_{2}$ coatings on mild steel substrate $\mathbf{c}$ aperture size $143 \mu \mathrm{m}$, d aperture size $1 \mathrm{~mm}$; and e optical image of $\mathrm{TiO}_{2}$ coatings. Scale bar equal to $200 \mathrm{~mm}$; non-

aperture sizes. As shown in Fig. 4a, a typical XRD profile shows iron (Fe) (PCPDF No. 00-006-0696) and Eskolaite $\mathrm{Cr}_{2} \mathrm{O}_{3}$ phase (PCPDF no. 00-038-1479). This is in line with as-grown $\mathrm{Cr}_{2} \mathrm{O}_{3}$ nanostructures [14] and the pure Eskolaite phase of green $\alpha-\mathrm{Cr}_{2} \mathrm{O}_{3}$ [25]. Similarly, the XRD pattern of $\mathrm{TiO}_{2}$ coating in Fig. $4 \mathrm{~b}$ showed a typical XRD profile consisting of $\mathrm{TiO}_{2}$ rutile (PCPDF No. 00-021-1276) and some anatase (PCPDF no. 00-021-1272) phase. These peaks are in line with $\mathrm{TiO}_{2}$ ceramics synthesized using solid-state reactions [20]. In the $\mathrm{TiO}_{2}$ coating, the iron oxide phase from the steel substrate appears $\left(\mathrm{Fe}_{2} \mathrm{O}_{4}, \mathrm{PCPDF}\right.$ no 00-039-1346). The presence of the rutile phase in $\mathrm{TiO}_{2}$ coatings might be contact profilometer images. $\mathbf{f} \mathrm{TiO}_{2}$ coatings on mild steel plate using 143- $\mu \mathrm{m}$ aperture, g $\mathrm{Cr}_{2} \mathrm{O}_{3}$ coatings on glass plate obtained using 1-mm aperture, $\mathbf{h} \mathrm{TiO}_{2}$ coatings on mild steel plate obtained using 1-mm aperture

due to partially molten, big particles, which were visible on the coating surface (Fig. 3c) [26]. During the APS process (with plasma temperature as high as $14,000 \mathrm{~K}$ (or $13,727^{\circ} \mathrm{C}$ ) and speed about $500 \mathrm{~m} / \mathrm{s}$ [27]), $\mathrm{TiO}_{2}$ particles can vapourise by the plasma stream. Consequently, the sprayed molten particles with high-temperature deposit on the substrate, and as the solidification temperature is close to the melting point of $\mathrm{TiO}_{2}$ (about $1843{ }^{\circ} \mathrm{C}$ ) the particles are apt to nucleate into stable rutile, and therefore, the rutile phase in the coating was also obtained [27].

As is known for thermally sprayed coatings, the existence of microstructural defects, high surface roughness,

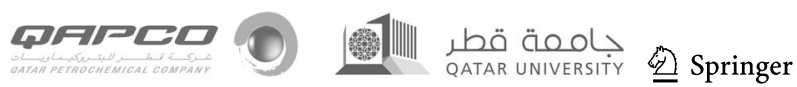


Fig. 3 a SEM micrograph of S-HVOF-sprayed $\mathrm{Cr}_{2} \mathrm{O}_{3}$ coating on mild steel substrate; the inset shows high-magnification micrograph; b EDS spectrum of $\mathrm{Cr}_{2} \mathrm{O}_{3}$ coating, $\mathbf{c}$ SEM micrograph of APS-sprayed $\mathrm{TiO}_{2}$ coatings on mild steel; the inset shows high-magnification micrograph; d EDS spectrum of $\mathrm{TiO}_{2}$ coating
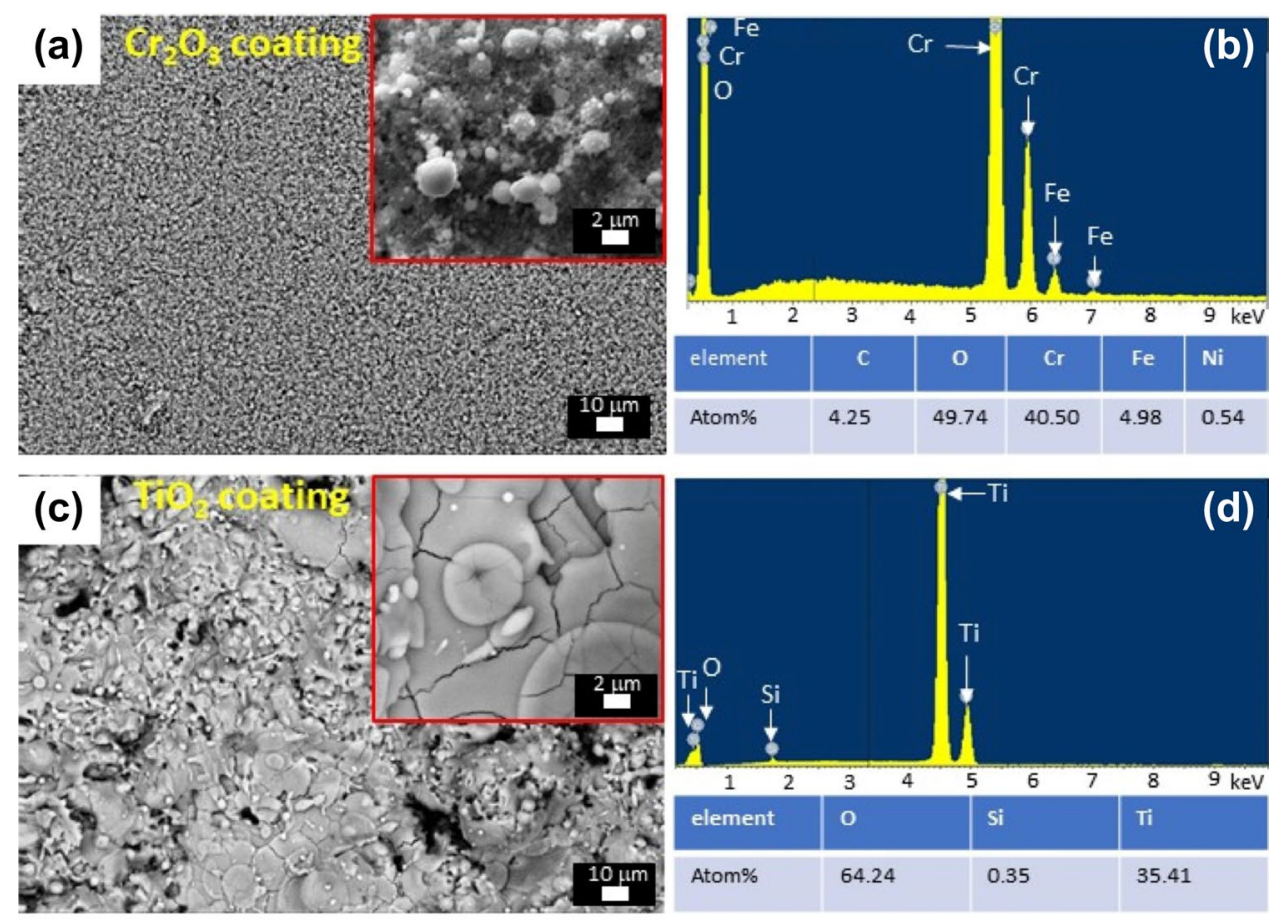

and phase contents lead to their poor optical (solar) properties, which limits the fabrication of solar selective absorbers. Nevertheless, with certain modification and fabrication techniques, thermally sprayed coatings can be developed for solar absorbing properties as demonstrated by Vaßen et al. [10] for $\mathrm{TiO}_{2}$ coatings and Bartuli et al. [12] for $\mathrm{Cr}_{2} \mathrm{O}_{3}$ coatings. To summarise, the morphological features, combined with the possibility of a fine control tailoring of the aperture field, thermal spray method, process parameter optimisation, and feedstock powder size can result in several interesting designs and material phases of coatings. Despite its discretized nature, the periodic configuration (single layer) or texture can be fabricated within an excellent approximation as a continuous sheet (large surface area) which can support and modify the electromagnetic wave propagation and its characteristics in various ranges (i.e., UV-Vis-IR region), as will be seen in the following section. Through this fabrication, an attempt was made to examine the interrelated trade-offs
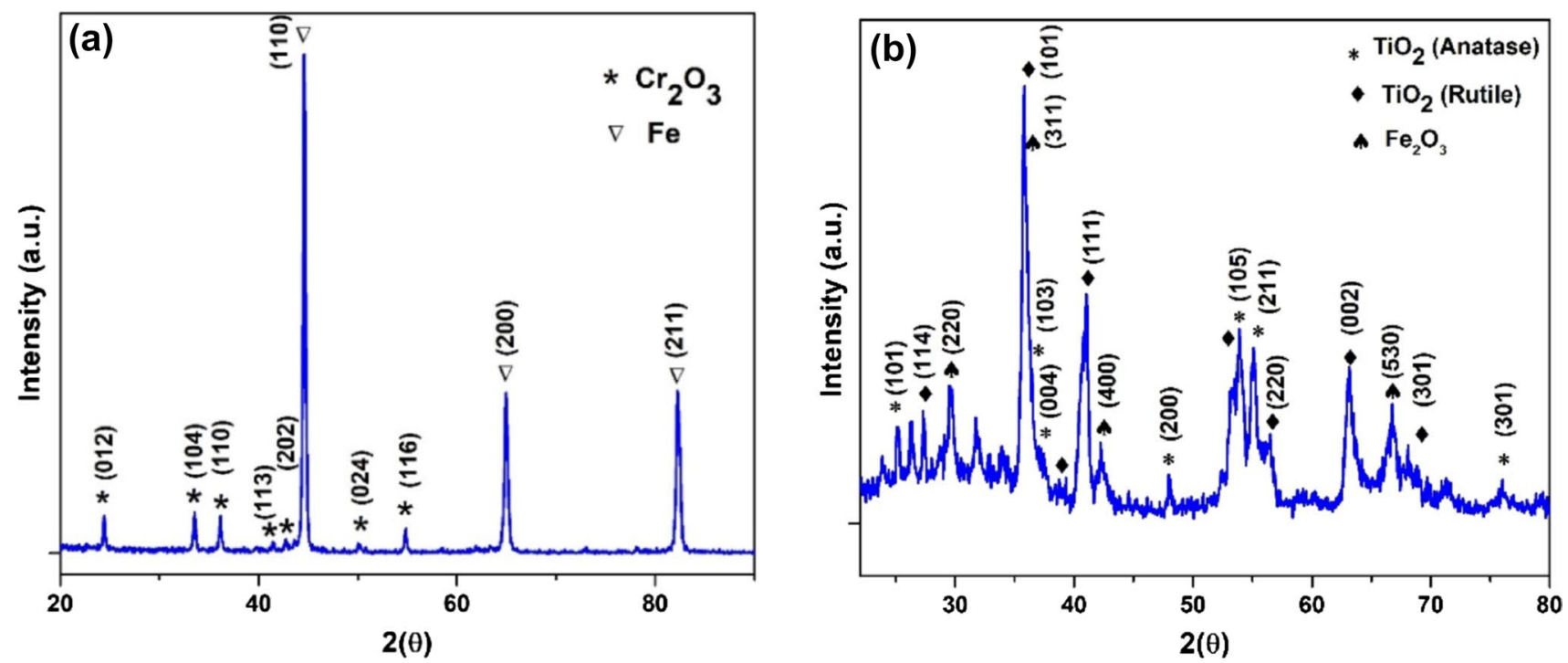

Fig. 4 XRD of artificial periodic 3D configuration coated samples on mild steel substrates (using $143 \mu \mathrm{m}$ aperture size): a S-HVOF-sprayed $\mathrm{Cr}_{2} \mathrm{O}_{3}$ coatings and $\mathbf{b}$ APS-sprayed $\mathrm{TiO}_{2}$ coatings

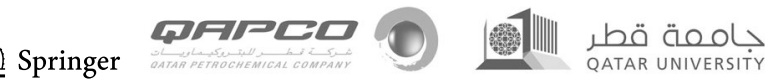


between the orthogonal structural designs, the fabrication limits, and the required material sets associated with building materials in large areas.

\subsection{Optical characterisation}

\subsubsection{S-HVOF-sprayed $\mathrm{Cr}_{2} \mathrm{O}_{3}$ coatings}

Figure 5 shows the reflectance curves in UV-Vis-IR range wavelength for S-HVOF-sprayed $\mathrm{Cr}_{2} \mathrm{O}_{3}$ coatings under different fabrication conditions and substrate types (refer to Table 1). A higher reflectance was observed for coatings fabricated using $143-\mu \mathrm{m}$ aperture compared to coatings fabricated using 1-mm aperture (more prominent in IR region). The difference in reflectance is due to the coating thickness created using the two aperture sizes. For $143-\mu \mathrm{m}$ and $1-\mathrm{mm}$ aperture, the thickness of the $\mathrm{Cr}_{2} \mathrm{O}_{3}$ coating was $124 \mathrm{~nm}$ and $755 \mathrm{~nm}$, respectively. Abedi and Gollo [28] found that the $\mathrm{Cr}_{2} \mathrm{O}_{3}$ coating showed increasing absorption and reduced reflectance. It would be interesting to investigate smaller aperture meshes to create thinner $\mathrm{Cr}_{2} \mathrm{O}_{3}$ coating that can achieve lower reflectance, especially in the IR wavelength range. The reflectance is higher for $143-\mu \mathrm{m}$ aperture compared to coatings fabricated using 1-mm aperture. The gun distance also plays a role in determining the absorbance/ reflectance. Between the two tested standoff distances of $85 \mathrm{~mm}$ and $120 \mathrm{~mm}$ (with aluminium substrates), the lower standoff distance leads to increased light absorbance shown in Fig. 5a because the gun near the substrate imparts the coating with characteristics such as uneven roughness, higher peening, and particle temperature at impacts, leading to greater deposition on surface asperities of the substrate [22].

\subsubsection{APS-sprayed $\mathrm{TiO}_{2}$ coatings}

Figures 6 shows optical spectroscopy curves for APSsprayed $\mathrm{TiO}_{2}$ coatings under different fabrication conditions and substrate types (mild steel, glass, ITO-coated glass, aluminium). Figure 6a compares the reflectance curves for APS $\mathrm{TiO}_{2}$ coatings on mild steel substrates. The comparison shows suppressed reflectance for all coatings throughout the spectrum. Suppressed reflectance or high absorption capability is possible as the addition of iron oxide in plasmasprayed $\mathrm{TiO}_{2}$ coating can improve absorption performance in the visual range of the coating [29]; however, in the current context, the potential formation of a thin layer of a new phase at the coating-substrate interface of steel substrate while spraying could be the speculated reasons for suppressed reflectance. It is also clear that it is little or no effect of mild steel substrates on the reflectance of all coatings fabricated using $143-\mu \mathrm{m}$ aperture or $1-\mathrm{mm}$ aperture sizes. Coatings on glass and ITO-coated glass substrates (Fig. 6b) show an enhanced reflectance trend. In the IR region, coatings fabricated using $143-\mu \mathrm{m}$ aperture shows relatively higher reflectance compared to coatings fabricated using 1-mm aperture. It was observed that there is an effect of glass or ITO-coated glass substrates on reflectance in the IR region of all coatings (relatively higher with glass than ITO-coated glass) fabricated using $143-\mu \mathrm{m}$ or 1-mm aperture sizes.

It is important to note that reflectance is an interface or surface phenomenon while transmittance is a bulk phenomenon [30]. Therefore, Fig. 6c, d shows transmittance curves for all glass substrates (glass, sand-blasted glass, ITO-coated glass, and sand-blasted ITO-coated glass). There are clear differences between glass (including the effect of sand blasting - reducing transmittance) and ITO coated glass throughout the spectrum. Figure $6 \mathrm{c}$ and d show transmittance curves (whereas Fig. 6e shows absorbance curves) for coatings on glass and ITO-coated glass substrates and it shows that the coatings fabricated using $143 \mu \mathrm{m}$ aperture shows very low transmittance (but higher absorbance) compared to coatings fabricated using $1 \mathrm{~mm}$ aperture, with the higher transmission in $\mathrm{TiO}_{2}$ coatings with ITO-coated glass substrates. However, the ITO-coated glass with $\mathrm{TiO}_{2}$ coatings has higher transmission compared to the glass with the same coating. This was observed for both $\mathrm{TiO}_{2}$ coatings: $1 \mathrm{~mm}$ and $143 \mu \mathrm{m}$. Overall, the results showed that
Fig. 5 Reflectance curves of the $\mathrm{S}$-HVOF sprayed $\mathrm{Cr}_{2} \mathrm{O}_{3}$ coatings under different fabrication conditions and substrate types: a 2-mm-thick aluminium, b 1-mm-thick mild steel, and 5-mm-thick mild steel
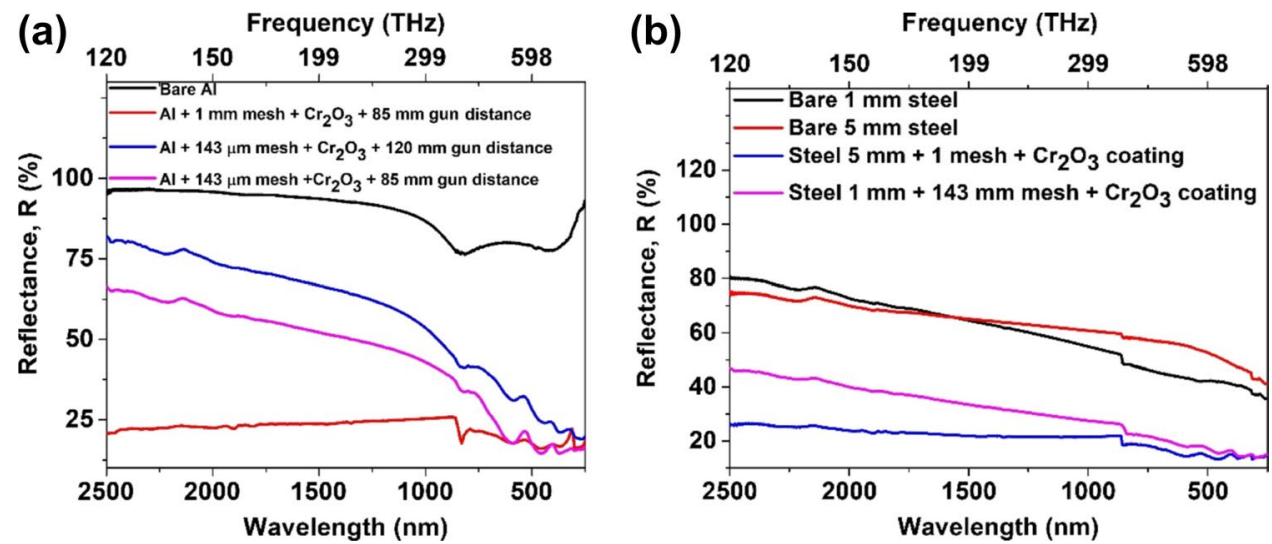
Fig. $6 \mathrm{TiO}_{2}$ coatings on different types of substrates. a Reflectance of $\mathrm{TiO}_{2}$ coating on mild steel with 1-mm and 143mm aperture size. b Reflectance of $\mathrm{TiO}_{2}$ coating on glass with 1-mm and 143-mm aperture size. $\mathbf{c}$ Transmittance of $\mathrm{TiO}_{2}$ coating on glass with 1-mm and 143-mm aperture size. $\mathbf{d}$ Transmittance of $\mathrm{TiO}_{2}$ coating on ITO coated glass with 1-mm and 143-mm aperture size. e Absorbance of $\mathrm{TiO}_{2}$ on glass and ITO-coated glass with 1-mm and 143-mm aperture size. $\mathbf{f}$ Reflectance of $\mathrm{TiO}_{2}$ coating on 2-mm-thick aluminium plate
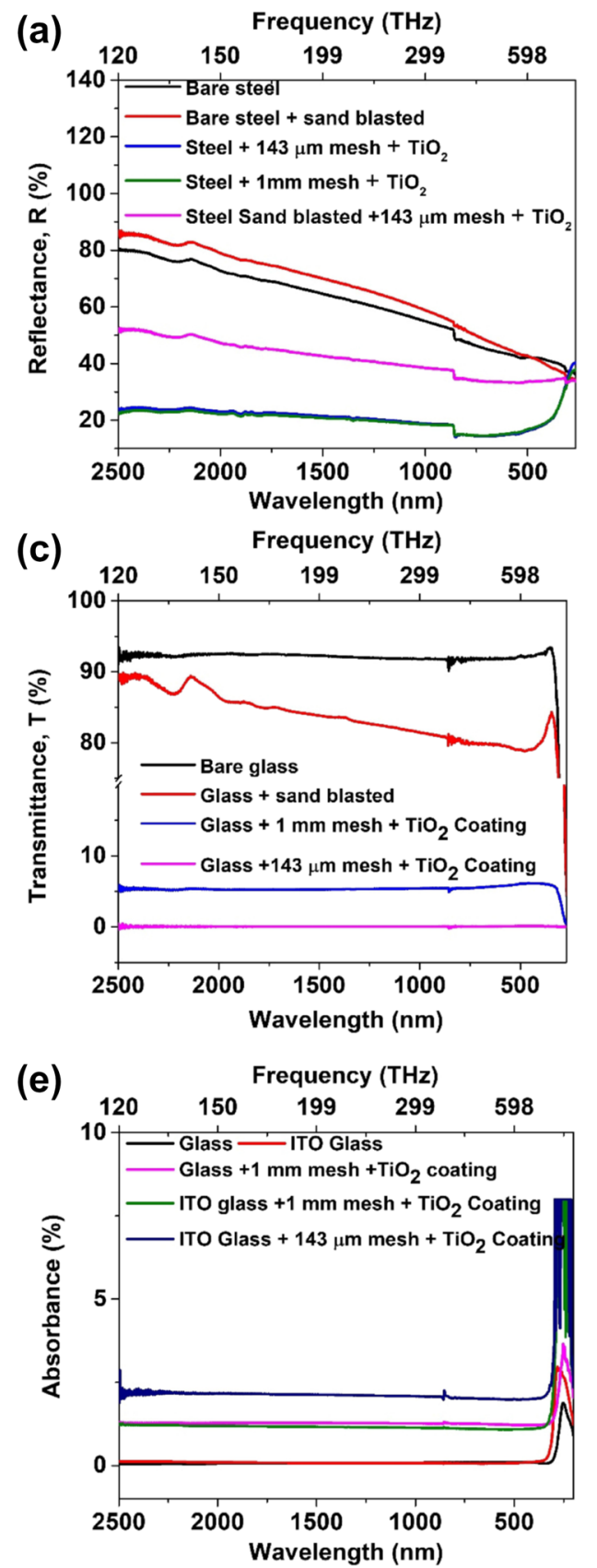
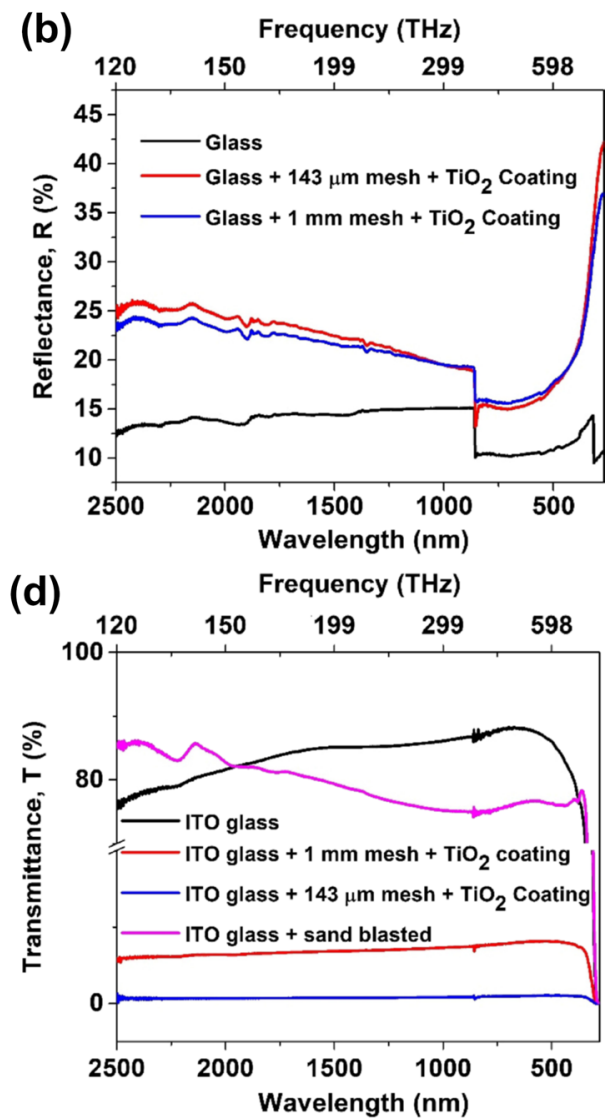

(d)

(f)

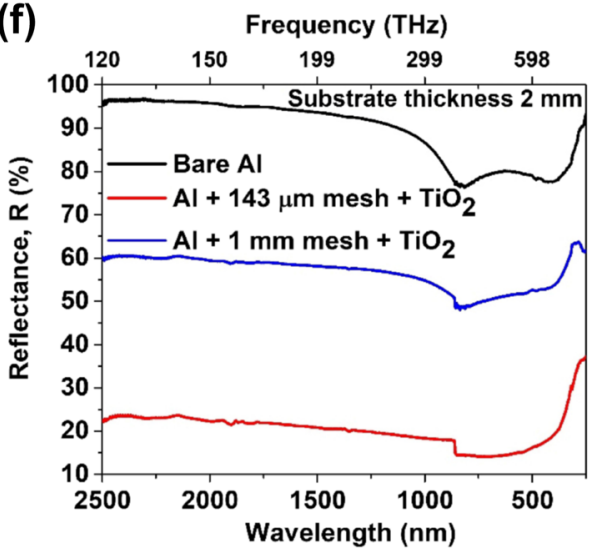

the $\mathrm{TiO}_{2}$ coating over glass and ITO coated with $143-\mathrm{mm}$ aperture size giving linear lowest transmittance (as well as linear highest absorbance), which means the coating is capable of absorbing radiation in the IR range. In addition, the 1-mm aperture coated substrate of $\mathrm{TiO}_{2}$ on glass/ITO glass has low transmittance, which is due to wide gaps in mesh uncoated area, where radiation passes through without trapped by the coating. Figure $6 f$ compares the reflectance curves for APS $\mathrm{TiO}_{2}$ coatings on aluminium substrates. The comparison shows reduced reflectance for all coatings (fabricated either using $143 \mu \mathrm{m}$ aperture or $1 \mathrm{~mm}$ aperture) throughout the spectrum. The reduction is more for coatings fabricated using a $143-\mu \mathrm{m}$ aperture compared to a $1-\mathrm{mm}$ aperture throughout the spectrum.

\subsection{Comparison between $\mathrm{Cr}_{2} \mathrm{O}_{3}$ and $\mathrm{TiO}_{2}$ coatings}

Electromagnetic properties of a given material govern the rate at which a material will respond to absorbed, reflected, or transmitted wave [31]. Since both $\mathrm{Cr}_{2} \mathrm{O}_{3}$ and $\mathrm{TiO}_{2}$ (rutile) materials possess a band gap of $3.0 \mathrm{eV}$, external energy illuminating photons with energy higher than this value are absorbed, causing electrons to pass from the valence band to the conduction band. $3.0 \mathrm{eV}$ corresponds to a wavelength 
of $413 \mathrm{~nm}\left(\lambda=\frac{h c}{E}=\frac{1240 \mathrm{eV} \cdot \mathrm{nm}}{3.0 \mathrm{eV}}=413 \mathrm{~nm}\right)$ which means that both $\mathrm{Cr}_{2} \mathrm{O}_{3}$ and $\mathrm{TiO}_{2}$ materials would absorb in the visible region of the spectrum. Considering the presence of lattice defects and grain boundaries, the light can diffuse and partially get absorbed [9]. However, in the current context, the metamaterial ceramic coatings $\left(\mathrm{Cr}_{2} \mathrm{O}_{3}, \mathrm{TiO}_{2}\right)$ deposited onto the metallic substrates (mild steel, aluminium) are expected to show complex behaviour as shown in Fig. 7 .

Figure 7a compares the reflectance curves between S-HVOF-sprayed $\mathrm{Cr}_{2} \mathrm{O}_{3}$ and APS-sprayed $\mathrm{TiO}_{2}$ coatings on 1-mm-thick mild steel substrate while spraying through 143$\mu \mathrm{m}$ aperture size. This also includes the reflectance of the coated surface which was entirely sand-blasted before coating (sand blasting is typically carried out so that the coatings could adhere better). Comparison between $\mathrm{Cr}_{2} \mathrm{O}_{3}$ and $\mathrm{TiO}_{2}$ coatings clearly shows suppressed reflectance for $\mathrm{TiO}_{2}$ coatings deposited on non-sand-blasted surface throughout the spectrum starting from $500 \mathrm{~nm}$, including strong absorption from 250 to $860 \mathrm{~nm}$. Comparison between $\mathrm{TiO}_{2}$ coatings deposited on sand-blasted and non-sand-blasted mild steel surface also shows suppressed reflectance for nonsand blasted surface throughout the spectrum starting from $300 \mathrm{~nm}$. Figure $7 \mathrm{~b}$ compares the reflectance curves between S-HVOF-sprayed $\mathrm{Cr}_{2} \mathrm{O}_{3}$ (sprayed through 1-mm aperture size) and APS sprayed $\mathrm{TiO}_{2}$ coatings (sprayed through $143 \mu \mathrm{m}$ and 1 -mm aperture sizes) on a 5-mm-thick mild steel substrate. Comparison results clearly show opposite reflectance trends up to $860 \mathrm{~nm}$ but similar trends between 860 and $2500 \mathrm{~nm}$. For a similar band gap in $\mathrm{Cr}_{2} \mathrm{O}_{3}$ and $\mathrm{TiO}_{2}$ materials $\left(\mathrm{E}_{\mathrm{g}} \approx 3.0 \mathrm{eV}\right)$, the optical properties of $\mathrm{Cr}_{2} \mathrm{O}_{3}$ coatings on mild steel fabricated through $143-\mu \mathrm{m}$ aperture size and mild steel fabricated through 1-mm aperture sizes are indeed better for opto-electronic devices from 250 to $400 \mathrm{~nm}$ (ultraviolet region). Figure 7c compares the reflectance curves between S-HVOF-sprayed $\mathrm{Cr}_{2} \mathrm{O}_{3}$ and APS-sprayed $\mathrm{TiO}_{2}$ coatings on 2-mm-thick aluminium substrate while spraying through 1-mm aperture sizes. Comparison results showed reduced reflectance (by three times) for $\mathrm{Cr}_{2} \mathrm{O}_{3}$ coatings throughout the spectrum. For a similar band gap in $\mathrm{Cr}_{2} \mathrm{O}_{3}$ and $\mathrm{TiO}_{2}$ materials, the optical properties of $\mathrm{Cr}_{2} \mathrm{O}_{3}$ coating on aluminium substrate were seen better throughout
Fig. 7 Comparison of reflectance curves between S-HVOFsprayed $\mathrm{Cr}_{2} \mathrm{O}_{3}$ and APS-sprayed $\mathrm{TiO}_{2}$ coatings under different fabrication conditions and substrates: a 1-mm-thick mild steel, b 5-mm-thick mild steel, and c 2-mm-thick aluminium
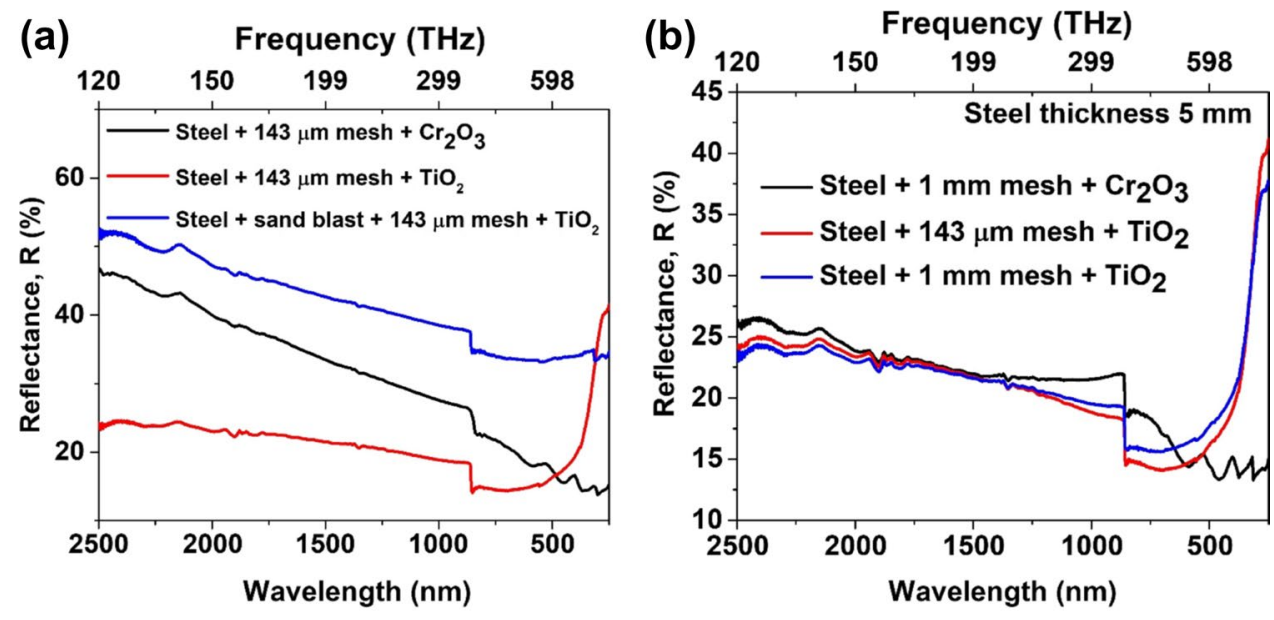

(c)

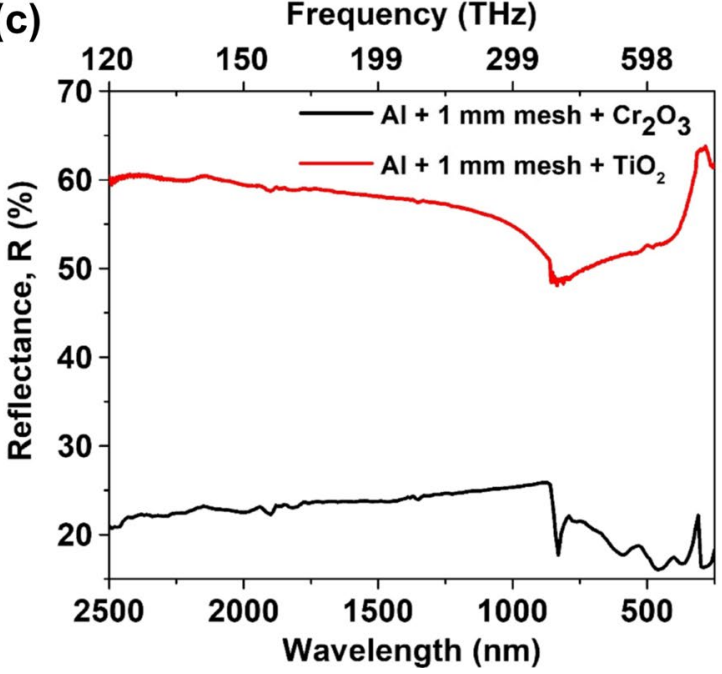


the spectrum ( 250 to $2500 \mathrm{~nm}$, i.e., $\mathrm{UV}-\mathrm{Vis}-\mathrm{IR}$ region). The presence of $\mathrm{TiO}_{2}$ coatings on aluminium substrate made significant changes in the behaviour of the IR band. These changes were more significant when the aluminium substrate was coated with $\mathrm{Cr}_{2} \mathrm{O}_{3}$.

During the deposition of $\mathrm{Cr}_{2} \mathrm{O}_{3}$ and $\mathrm{TiO}_{2}$ by S-HVOF and APS spraying, respectively, the molten or partially molten powders were accelerated to strike the substrate. Because of the complexity of the particle impact position through the masking sheet (aperture/mesh sizes of $143 \mu \mathrm{m}$ and $1 \mathrm{~mm}$ ) and the particle distribution, microstructurally, the surface of both coatings was uneven and porous (see Fig. 3a, c). Due to the accumulation of sprayed particles on the surface in the form of periodic 3D configuration (orthogonal structure), such structures with a large roughness led to a surface that acts as a radiation trap, so that the coating absorbs more wave energy in the IR region. The overall coating performance is better in IR range absorption due to the fine size powder of $\mathrm{Cr}_{2} \mathrm{O}_{3}$, which means that the suspension can penetrate the masking aperture to fill the valley onto the substrate and make the perfect building block (orthogonal structure) of coatings (geometrical manipulation). It has been observed that the height of $\mathrm{Cr}_{2} \mathrm{O}_{3}$ coating (between 124 and $755 \mathrm{~nm}$ ) is lower than $\mathrm{TiO}_{2}$ coating (between 12 and $17 \mu \mathrm{m}$ ). The roughness (i.e., global roughness and roughness within the orthogonal block faces) is important to compare because the surface roughness of the coatings can be used to control the absorbance. It has been reported theoretically that when the spatial frequency of the surface roughness is longer than the wavelength of the electromagnetic waves, the wave can be arrested by multiple reflections, thereby contributing to higher absorbance. Therefore, larger roughness could potentially facilitate enriched spectral absorbing property from the thermally sprayed coatings [32]. In the example, the height of the orthogonal structure (at least some part) can be shorter than the wavelength of the electromagnetic waves (250 to $2500 \mathrm{~nm}$ ) for $\mathrm{Cr}_{2} \mathrm{O}_{3}$ coatings; therefore, the part surface can act as a mirror for these long wavelengths, and most of the IR light would be reflected from such area of the surface, while trapped due to orthogonal coating building blocks. The roughness within the orthogonal block for $\mathrm{TiO}_{2}$ coatings was covered by micro-pores, through which the solar rays could penetrate to the substrate and consequently weaken the intended spectrally selective effect of the deposited coating. As for the as-sprayed $\mathrm{TiO}_{2}$ coatings, shown in Fig. 3c, the coating became much denser with fewer micro-pores. This difference can be attributed to the process of improved melting of sprayed particles during plasma spraying. However, laser treatment [33] of both coatings $\left(\mathrm{Cr}_{2} \mathrm{O}_{3}, \mathrm{TiO}_{2}\right)$ could improve or eliminate micropores or cracks, leading to a strong spectrally selective effect of the deposited coating.

To summarise, the feedstock and substrate material selection, deposition technique, microstructure, and metamaterial building block (orthogonal structure and size) of coatings can have a distinct electromagnetic wave propagation characteristic. This can be appreciated further, as demonstrated by Shahbazi et al. [30] who suggested while investigating ceramic materials with prominent transparency and admissible transmittance in selective wavelengths that absorption, reflection, refraction, and scattering are the factors that can harm the degree of transparency. Such factors are convoluted; i.e., absorption depends on the energy gap of the material, the presence of impurities and the presence of crystalline defects in the materials, and the reflection depends on the surface properties, the incident light angle, the temperature, and the wavelength of the materials. Scattering affects the transparency, and the factors affecting the amount of light scattering can be attributed to the material porosity, the difference between the refractive index of grain and grain boundary, and the grain size, etc. Therefore, controlling each of these factors during thermal spray coating can play a crucial role in achieving desirable electromagnetic wave propagation (absorption, reflection, refraction, scattering, transmission) in samples with ceramic coatings deposited onto glass or metallic substrates.

\section{Future directions}

Metamaterial fabrication using thermal spray techniques is poised to make a huge impact primarily because it can change electromagnetic radiations as demonstrated recently by Shao et al. [19] for enhanced radar absorption applications. The thermal spray coating technique can be a viable method to design surface structures to synthesize a newer category of metamaterials. It is anticipated that thermally sprayed metamaterial coating layers can achieve desired effects by incorporating structural elements of sub-wavelength sizes, i.e., features that are smaller than the wavelength of the waves they affect.

This study presents the mass-producible 3D fabrication of thermally sprayed artificial periodic configuration coatings (single layer or a planar structure) where the unit elements are not smaller than the wavelength of light (typically defined in nanoscale 'metamaterial' fabrication [2]). The fabricated micro-scale coating structure can make changes or control the light waves using the functionalities that arise from these single-layer artificial structures, potentially as electromagnetic shields, heat-sensitive substrates or antennas (e.g., rectennas [1,34]). It has been suggested by Bailey [35] that broadband rectifying antennas (or rectennas) could be used for solar energy to directcurrent (DC) conversion. Rectennas for solar conversion would have dimensions on the order of the wavelengths of solar radiation that falls mostly in the sub-micron range [1]. Rectennas has been demonstrated to have achieved 
very highly efficient conversion, exceeding $80 \%$, to DC electricity from monochromatic microwave radiation, as reviewed by Goswami et al. [36].

A review by Boltasseva and Shalaev [37] suggested that the future issue in this direction will be to address the development of truly three-dimensional (3D) metamaterials in the optical range, and the challenging tasks are to move from planar structures to a 3D slab of layered metamaterial, to develop new isotropic designs and to outline alternative manufacturing techniques (e.g., deposition of metal and dielectric on a substrate) that can be adapted to future metamaterial fabrication. Applications of the thermal spray technique are easy for planar structure fabrication but are challenging if the same technique is considered to fabricate a 3D slab of layered metamaterial and fabricate new isotropic designs. It has also been suggested that for improved performance of metamaterial, higher complexity and multi-step deposition procedures are required in a chosen approach of coating deposition [37]. This could involve the selection of a range of standard process parameters for experimental validation of metamaterial (e.g., optics, photonics) properties, including the application of micro/nano-fabrication techniques, such as photolithography and EB lithography [2]. Doping can also help modify optical properties, as demonstrated by Tului et al. [9], where doping of metal oxides (e.g., high concentration of $\mathrm{n}$-doping $\mathrm{Al}$ atoms presence in $\mathrm{ZnO}$ lattice), fabricated using air plasma spray technique, can modify its optical emissivity in the infrared region. An improved 'metamaterial' or 'metastructure' design could involve a combination of additional coating methods for layer-by-layer functionalities. This could be molecular beam epitaxy, hydride vapour phase epitaxy, liquid phase epitaxy, metal-organic molecular beam epitaxy, atomic layer deposition, including vapour deposition, and dip coating for the formation of semiconducting coatings for devices. These metastructures have their application in transformation optics where the manipulation of relative permittivity is carried out using metamaterials or artificially deigned materials or composites which in turn can tune the refractive index for graded-index (GRIN) devices such as a flat hyperbolic lens. These materials have been designed using micro and nanoparticles of titanates using vacuum casting [38].

While the DC output measurement, assessing the rectification effects under solar radiation and modelling, can be part of further work, it has been demonstrated through this work that the application of thermal spray coating method can be a useful means to manufacture sunlight absorbing meta-surfaces (scalable) and potentially a rectenna system (i.e., transmitting power by UV-Vis-IR region electromagnetic waves) for solar-powered satellites, sensors, drones, planetary missions, etc.

\section{Conclusions}

There is a need to address the inability to adequately manufacture large-scale metamaterial coatings. In this study, the feasibility of large-scale fabrication of artificial periodic planar configuration of coatings by thermal spraying for tailored electromagnetic properties (in the solar spectrum between 250 and $2500 \mathrm{~nm}$; i.e., scan range is from UV-Vis-NIR light) is demonstrated for the first time. Two different semiconductor transition metal-oxide oxides (i.e., $\mathrm{Cr}_{2} \mathrm{O}_{3}, \mathrm{TiO}_{2}$ ) were deposited and analysed. Combinatorial changes in the materials and manufacturing process parameters including the substrate materials (mild carbon steel, aluminium, glass, indium tin oxide (ITO) coated glass), deposition techniques (S-HVOF for $\mathrm{Cr}_{2} \mathrm{O}_{3}$, APS for $\mathrm{TiO}_{2}$ ), aperture sizes $(143 \mu \mathrm{m}, 1 \mathrm{~mm})$ have led to the identification of the most suitable classes of materials to be used to produce functional single-layer coatings with improved optical properties. While using the liquid deposition technique ( $\mathrm{S}-\mathrm{HVOF}$ for $\mathrm{Cr}_{2} \mathrm{O}_{3}$ coatings), the mean height of the orthogonal structure varies between 124 and $755 \mathrm{~nm}$, whereas for the conventional deposition technique (APS for $\mathrm{TiO}_{2}$ coatings), the mean height of the orthogonal structure varies between 12 and $17 \mu \mathrm{m}$. The reflectance of the coating demonstrates that both coatings are suitable for optical absorption applications, but it largely depends on the substrate types and masking aperture sizes. Comparison between $\mathrm{Cr}_{2} \mathrm{O}_{3}$ and $\mathrm{TiO}_{2}$ coatings on aluminium substrates clearly showed three order reduced reflectance for $\mathrm{Cr}_{2} \mathrm{O}_{3}$ coatings (fabricated through 1-mm aperture size) throughout the spectrum. Therefore, for a similar band gap $\left(\mathrm{E}_{\mathrm{g}} \approx 3.0 \mathrm{eV}\right)$ in $\mathrm{Cr}_{2} \mathrm{O}_{3}$ and $\mathrm{TiO}_{2}$ materials, the optical properties of $\mathrm{Cr}_{2} \mathrm{O}_{3}$ coating on aluminium substrate are expected to provide better opto-electronic devices. Apart from conventional thermal spray techniques (e.g., APS, HVOF), with the advancement in the use of liquid deposition techniques (e.g., S-HVOF) which can enable manufacturing finely grained (nanometre, sub-micrometre) composite coatings, future work may be promising in the current context, as it can allow convenient deposition of range of coatings to yield distinct electromagnetic wave properties.

CRediT authorship contribution statement Nadimul Haque Faisal: conceptualisation, data curation, formal analysis, funding acquisition, investigation, methodology, software, project administration, resources, validation, writing — original draft. Nazmi Sellami: funding acquisition, investigation, methodology, software, validation, writing - review and editing. Federico Venturi: investigation, methodology, resources, writing-review and editing. Tanvir Hussain: funding acquisition, resources, writing - review and editing. Tapas Mallick: funding acquisition, resources, writing - review and editing. Firdaus MuhammadSukki: funding acquisition, writing - review and editing. Alex Bishop: methodology, formal analysis, writing — review and editing. Hari 
Upadhyaya: validation, writing — review and editing. Nirmal Kumar Katiyar: editing, data plotting, and reviewing. Saurav Goel: funding acquisition, resources, formal analysis, writing — review and editing.

Funding This work is supported by the Pump Priming Funding at Robert Gordon University, Aberdeen (Project ID: 232073: Thermally sprayed metamaterial coatings for photovoltaic energy harvesting applications (\#themetacoat)). Author (SG) is also thankful to the research support provided by the UKRI via Grants No. EP/L016567/1, EP/S013652/1, EP/T001100/1, EP/S036180/1 and EP/T024607/1. Additionally, the support received from H2020 (EMPIR (A185), Cost Actions CA18125, CA18224, CA17136 and CA16235), Royal Academy of Engineering via Grants No. IAPP18-19\295, TSP1332 and EXPP2021\11277 and Newton Fellowship award from the Royal Society (NIF\R1\191571) is also acknowledged. SG also accessed the Isambard Bristol, UK, supercomputing service via Resource Allocation Panel (RAP) as well as ARCHER2 resources (Project e648).

Data availability All data in the manuscript will be available through Robert Gordon University and Cranfield University data repository (https://doi.org/10.48526/rgu-wt-1369280).

\section{Declarations}

Conflict of interest The authors declare no competing interests.

Open Access This article is licensed under a Creative Commons Attribution 4.0 International License, which permits use, sharing, adaptation, distribution and reproduction in any medium or format, as long as you give appropriate credit to the original author(s) and the source, provide a link to the Creative Commons licence, and indicate if changes were made. The images or other third party material in this article are included in the article's Creative Commons licence, unless indicated otherwise in a credit line to the material. If material is not included in the article's Creative Commons licence and your intended use is not permitted by statutory regulation or exceeds the permitted use, you will need to obtain permission directly from the copyright holder. To view a copy of this licence, visit http://creativecommons.org/licenses/by/4.0/.

\section{References}

1. T.M. Razykov, C.S. Ferekides, D. Morel, E. Stefanakos, H.S. Ullal, H.M. Upadhyaya, Solar photovoltaic electricity: current status and future prospects. Sol. Energy 85, 1580-1608 (2011). https://doi.org/10.1016/j.solener.2010.12.002

2. M. Faenzi, G. Minatti, D. González-Ovejero, F. Caminita, E. Martini, C.D. Giovampaola, S. Maci, Metasurface antennas: new models, applications and realizations. Sci Rep 9, 10178 (2019). https://doi.org/10.1038/s41598-019-46522-z

3. T. Tanaka, A. Ishikawa, Towards three-dimensional optical metamaterials. Nano Converg 4, 34 (2017). https://doi.org/10.1186/ s40580-017-0129-7

4. M. Sağık, O. Altıntaş, E. Ünal, M. Demirci, S. Colak, M. Karaaslan, Optimizing the gain and directivity of a microstrip antenna with metamaterial structures by using artificial neural network approach. Wireless Pers. Commun. 118, 109-124 (2021). https://doi.org/10.1007/s11277-020-08004-8

5. Y.I. Abdulkarim, L.-W. Deng, J.-L. Yang, S. Colak, M. Karaaslan, S.-X. Huang, L.-H. He, H. Luo, Tunable left-hand characteristics in multi-nested square-split-ring enabled metamaterials. J
Cent South Univ 27, 1235-1246 (2020). https://doi.org/10.1007/ s11771-020-4363-5

6. I. Brener, S. Liu, I. Staude, J. Valentine, C. L. Holloway (Ed.), Dielectric metamaterials: fundamentals, designs, and applications, $1^{\text {st }}$ Edition, 2019, Woodhead Publishing, eBook ISBN: 9780081024041.

7. M. Askari, D.A. Hutchins, P.J. Thomas, L. Astolfi, R.L. Watson, M. Abdi, M. Ricci, S. Laureti, L. Nie, S. Freear, R. Wildman, C. Tuck, M. Clarke, E. Woods, A.T. Clare, Additive manufacturing of metamaterials: A review. Addit. Manuf. 36, 101562 (2020). https://doi.org/10.1016/j.addma.2020.101562

8. S. Goel, N.H. Faisal, V. Ratia, A. Agrawal, A. Stukowski, Atomistic investigation on the structure-property relationship during thermal spray nanoparticle impact. Comput. Mater. Sci. 84, 163 174 (2014). https://doi.org/10.1016/j.commatsci.2013.12.011

9. M. Tului, F. Arezzo, L. Pawlowski, Optical properties of plasma sprayed $\mathrm{ZnO}+\mathrm{Al}_{2} \mathrm{O}_{3}$ coatings. Surf. Coat. Technol. 179(1), 47-55 (2004). https://doi.org/10.1016/S0257-8972(03)00800-4

10. R. Vaßen, Z. Yi, H. Kaßner, D. Stöver, Suspension plasma spraying of $\mathrm{TiO}_{2}$ for the manufacture of photovoltaic cells. Surf. Coat. Technol. 203(15), 2146-2149 (2009). https://doi.org/10.1016/j. surfcoat.2008.10.021

11. M. Bégard, K. Bobzin, G. Bolelli, A. Hujanen, P. Lintunen, D. Lisjak, S. Gyergyek, L. Lusvarghi, M. Pasquale, K. Richardt, T. Schläfer, T. Varis, Thermal spraying of Co, Ti-substituted Ba-hexaferrite coatings for electromagnetic wave absorption applications. Surf. Coat. Technol. 203(20-21), 3312-3319 (2009). https://doi. org/10.1016/j.surfcoat.2009.04.007

12. C. Bartuli, F. Cipri, T. Valente, Thermal spraying and the fabrication of coatings with tailored electromagnetic properties. Inorg. Chim. Acta 361(14-15), 4077-4088 (2008). https://doi.org/10. 1016/j.ica.2008.03.063

13. X.Q. Deng, M.M. Xue, Y.L. Lv, R.H. Li, J.M. Tong, G.H. Shi, Y. Yang, Y.C. Dong, Study on spectral selective absorbing coatings with spinel structures fabricated via plasma spraying. Vacuum 174, 109214 (2020). https://doi.org/10.1016/j.vacuum.2020. 109214

14. M.M. Abdullah, M. Fahd Rajab, M. Saleh Al-Abbas, Structural and optical characterization of $\mathrm{Cr}_{2} \mathrm{O}_{3}$ nanostructures: evaluation of its dielectric properties. AIP Advances 4, 027121 (2014). https:// doi.org/10.1063/1.4867012

15. A.E. Freitas, T.M. Manhabosco, R.J.C. Batista, A.K.R. Segundo, H.X. Araújo, F.G.S. Araújo, A.R. Costa, Development and characterization of titanium dioxide ceramic substrates with high dielectric permittivities. Materials 13(2), 386 (2020). https://doi.org/10. 3390/ma13020386

16. K. Wen, M. Liu, X. Liu, C. Deng, K. Zhou, Deposition of photocatalytic $\mathrm{TiO}_{2}$ coating by modifying the solidification pathway in plasma spraying. Coatings 7(10), 169 (2017). https://doi.org/10. 3390/coatings 7100169

17. C. Dette, M.A. Perez-Osorio, C.S. Kley, P. Punke, C.E. Patrick, P. Jacobson, F. Giustino, S.J. Jung, K. Kern, $\mathrm{TiO}_{2}$ anatase with a bandgap in the visible region. Nano Lett. 14, 6533-6538 (2014). https://doi.org/10.1021/n1503131s

18. A. Wypych, I. Bobowska, M. Tracz, A. Opasinska, S. Kadlubowski, A. Krzywania-Kaliszewska, J. Grobelny, Piotr Wojciechowski, Dielectric properties and characterisation of titanium dioxide obtained by different chemistry methods. J. Nanomater. 124814, 9 (2014). https://doi.org/10.1155/2014/124814

19. T. Shao, H. Ma, J. Wang, M. Yan, M. Feng, Z. Yang, Q. Zhou, J. Wang, Y. Meng, S. Zhao, S. Qu, Ultra-thin and high temperature NiCrAlY alloy metamaterial enhanced radar absorbing coating. J. Alloy. Compd. 832, 154945 (2020). https://doi.org/10.1016/j. jallcom.2020.154945

20. G. M. Swain, 5 - Solid electrode materials: pretreatment and activation, Editor(s): Cynthia G. Zoski, Handbook of 
Electrochemistry, Elsevier, 111-153 (2007). https://doi.org/10. 1016/B978-044451958-0.50006-9

21. M. Bai, H. Maher, Z. Pala, T. Hussain, Microstructure and phase stability of suspension high velocity oxy-fuel sprayed yttria stabilised zirconia coatings from aqueous and ethanol based suspensions. J. Eur. Ceram. Soc. 38(4), 1878-1887 (2018). https://doi. org/10.1016/j.jeurceramsoc.2017.10.026

22. J. Kiilakoski, R. Trache, S. Björklund, S.V. Joshi, P. Vuoristo, Process parameter impact on suspension-HVOF-sprayed $\mathrm{Cr}_{2} \mathrm{O}_{3}$ coatings. J. Therm. Spray Technol. 28, 1933-1944 (2019). https:// doi.org/10.1007/s11666-019-00940-7

23. D. Tejero-Martin, Z. Pala, S. Rushworth, T. Hussain, Splat formation and microstructure of solution precursor thermal sprayed Nb-doped titanium oxide coatings. Ceram. Int. 46(4), 5098-5108 (2020). https://doi.org/10.1016/j.ceramint.2019.10.253

24 D. Tejero-Martin, M. Rezvani Rad, A. McDonald, T. Hussain, Beyond traditional coatings: a review on thermal-sprayed functional and smart coatings. J. Therm. Spray Technol. 28, 598-644 (2019). https://doi.org/10.1007/s11666-019-00857-1

25. B.T. Sone, E. Manikandan, A. Gurib-Fakim, M. Maaza, Singlephase $\alpha-\mathrm{Cr}_{2} \mathrm{O}_{3}$ nanoparticles' green synthesis using Callistemon viminalis' red flower extract. Green Chem. Lett. Rev. 9(2), 85-90 (2016). https://doi.org/10.1080/17518253.2016.1151083

26. R. Tomaszek. Pawlowski. Gengembre, Laureyns. Znamirowski. Zdanowski, Microstructural characterization of plasma sprayed $\mathrm{TiO}_{2}$ functional coating with gradient of crystal grain size, Surface \& Coatings Technology, 201(1-2), 45-56https://doi.org/10.1016/j. surfcoat.2005.10.033

27. J. Cizek, K.A. Khor, I. Dlouhy, In-flight temperature and velocity of powder particles of plasma-sprayed $\mathrm{TiO}_{2}$. J. Therm. Spray Technol. 22, 1320-1327 (2013). https://doi.org/10.1007/ s11666-013-9993-9

28. H.R. Abedi, M.H. Gollo, An experimental study of the effects of surface roughness and coating of $\mathrm{Cr}_{2} \mathrm{O}_{3}$ layer on the laser-forming process. Opt. Laser Technol. 109, 336-347 (2019). https://doi.org/ 10.1016/j.optlastec.2018.07.064

29. F. Ye, A. Ohmori, The photocatalytic activity and photo-absorption of plasma sprayed $\mathrm{TiO}_{2}-\mathrm{Fe}_{3} \mathrm{O}_{4}$ binary oxide coatings. Surf. Coat. Technol. 160(1), 62-67 (2002). https://doi.org/10.1016/ S0257-8972(02)00377-8
30. H. Shahbazi, M. Tataei, M.H. Enayati, A. Shafeiey, M. Azizi, Malekabadi, Structure-transmittance relationship in transparent ceramics. J. Alloy. Compd. 785, 260-285 (2019). https://doi.org/ 10.1016/j.jallcom.2019.01.124

31. A. Ishimaru, Electromagnetic wave propagation, radiation, and scattering: From fundamentals to applications, $2^{\text {nd }}$ ed., Wiley, 2017, Online ISBN: 9781119079699. https://doi.org/10.1002/ 9781119079699

32. S. Dosta, M. Robotti, S. Garcia-Segura, E. Brillas, I.G. Cano, J.M. Guilemany, Influence of atmospheric plasma spraying on the solar photoelectro-catalytic properties of $\mathrm{TiO}_{2}$ coatings. Appl. Catal. B 189, 151-159 (2016). https://doi.org/10.1016/j.apcatb.2016.02. 048

33. Y. Gao, J. Xiong, D. Gong, J. Li, M. Ding, Improvement of solar absorbing property of Ni-Mo based thermal spray coatings by laser surface treatment. Vacuum 121, 64-69 (2015). https://doi. org/10.1016/j.vacuum.2015.07.018

34. E. Donchev, J.S. Pang, P.M. Gammon, A. Centeno, F. Xie, P.K. Petrov, J.D. Breeze, M.P. Ryan, D.J. Riley, N.M. Alford, The rectenna device: from theory to practice (a review). MRS. Energ. Sustain. 1, 1 (2014). https://doi.org/10.1557/mre.2014.6

35. R.L. Bailey, A proposed new concept for a solar energy convertor. J. Eng. Power 94(2), 73-77 (1972). https://doi.org/10.1115/1. 3445660

36. D.Y. Goswami, S. Vijayaraghavan, S. Lu, G. Tamm, New and emerging developments in solar energy. Sol. Energy 76(1-3), 33-43 (2004). https://doi.org/10.1016/S0038-092X(03)00103-8

37. A. Boltasseva, V.M. Shalaev, Fabrication of optical negative-index metamaterials: recent advances and outlook. Metamaterials 2(1), 1-17 (2008). https://doi.org/10.1016/j.metmat.2008.03.004

38. S.S. Bukhari, W.G. Whittow, S. Zhang, J.C. Vardaxoglou, Composite materials for microwave devices using additive manufacturing. Electron. Lett. 52(10), 832-833 (2016). https://doi.org/10. 1049/el.2016.0078

Publisher's Note Springer Nature remains neutral with regard to jurisdictional claims in published maps and institutional affiliations.

\section{Authors and Affiliations}

\section{Nadimul Haque Faisal ${ }^{1} \cdot$ Nazmi Sellami $^{1} \cdot$ Federico Venturi $^{2} \cdot$ Tanvir Hussain $^{2} \cdot$ Tapas Mallick $^{3}$. Firdaus Muhammad-Sukki ${ }^{4}$ Alex Bishop ${ }^{5} \cdot$ Hari Upadhyaya ${ }^{6} \cdot$ Nirmal Kumar Katiyar $^{6} \cdot$ Saurav Goel ${ }^{5,6,7}$}

1 School of Engineering, Robert Gordon University, Garthdee Road, Aberdeen AB10 7GJ, UK

2 Faculty of Engineering, University of Nottingham, Nottingham NG7, 2RD, UK

3 Environment and Sustainability Institute, University of Exeter, Penryn Campus, Penryn TR109FE, Cornwall, UK

4 School of Engineering and Built Environment, Edinburgh Napier University, Merchiston Campus, 10 Colinton Road, Edinburgh EH10 5DT, UK
5 School of Aerospace, Transport and Manufacturing, Cranfield University, Bedfordshire MK43 0AL, UK

6 School of Engineering, London South Bank University, 103 Borough Road, London SE1 0AA, UK

7 Department of Mechanical Engineering, Shiv Nadar University, Gautam Budh Nagar, Uttar Pradesh 201314, India 